\title{
Pre and Postprandial Thermographic Profile of Green Iguanas (Iguana iguana)
}

\author{
Simona RUSU ${ }^{1 *}$, Zdenek KNOTEK ${ }^{2}$, Radu LĂCĂTUȘ ${ }^{1}$ and Ionel PAPUC ${ }^{1}$ \\ ${ }^{1}$ Department of Semiology. University of Agricultural Sciences and Veterinary Medicine, Calea \\ Mănăștur 3-5 400372, Cluj Napoca, Romania \\ ${ }^{2}$ Reptile Clinic. University of Pharmaceutical and Veterinary Sciences, Palackeho tr. 1946/1, 612 42, Brno, \\ Czech Republic \\ *corresponding author: simona_rusu_vet@yahoo.ro
}

Bulletin UASVM Veterinary Medicine 73(2) / 2016,

Print ISSN 1843-5270; Electronic ISSN 1843-5378

DOI:10.15835/buasvmcn-vm: 12345

\begin{abstract}
The body temperature of 10 clinically healthy green iguanas (Iguana iguana) was measured using a thermographic camera (FLIR E6, Flir Systems Sweden) before and after the food was offered. For each animal there were performed a total of 6 measurements ( 3 before feeding and 3 after the food was offered). The purpose of this experiment was to observe the thermographic pattern of the body before and after the feeding, since herbivore reptiles tend to bask after the feeding to increase the body temperature that will help them afterwards digest the food. The animals were housed in individual vivariums with every animal having a basking spot available. The images were taken outside the vivarium in an adjacent room. The animals were handled with gloves and transported in a cardboard box in order to avoid heat transfer between the handler and the iguana that would have produced thermal artefacts. Each individual was placed on a table on a styrofoam slate, again, to avoid the heat transfer between the table and the animal's body. For each animal a total of 4 pictures were taken (up, front, left and right). The images were analysed with the FLIR Tools program that is provided by the manufacturer and 3 temperatures were taken into consideration (the head temperature, body temperature on the right side and body temperature on the left side). The temperatures were compared between them and with the temperature of the vivariums that consisted of the average between the temperature in 3 different spots (basking spot, the feeding bowl site and the coldest spot) measured with an infrared thermometer GM300 (Benetech, China). The temperature of the body was dependent on the vivarium temperature and it was a significant temperature difference between the measurements before the feeding and after the feeding. Also we discovered a significant difference between the head temperature and the body temperature on the left side before feeding that disappeared after the animals ate. There was also a significant difference between the temperature on right side and on left side of the body both before and after the feeding. No significant temperature difference was observed between the head and the right side of the body neither before nor after feeding.
\end{abstract}

Keywords: feeding, green iguana, temperature, thermography.

\section{INTRODUCTION}

With a few exceptions, reptiles are exclusively ectotherms, which makes them dependent on the environmental temperature for their thermoregulation. In 1965 Brattstorm classifies the reptiles depending on their thermoregulation method. Green iguanas are reptiles that bask in the sun to thermoregulate.
In this study, a thermographic camera was used (FLIR E6-Flir Systems, Sweden) to measure the reptile body temperature and its thermographic pattern. Like all other processes and activities, in reptiles everything is dependent on temperature. For digestion, depending on the species, there is an interval of temperature from which the digestion starts and becomes more efficient as 
the temperature rises. Herbivore reptiles need a higher temperature for digestion compared to carnivores (Harlow et. al., 1976).

One of the first studies that measured the temperature of iguanas in more than one area was performed by Spray et. al. (1973) and used the invasive method of telethermometres inserted in different regions of the body. Thermography on the other hand, having the disadvantage of using only the surface temperature, is a non-invasive method that also brings a minimum of stress to the animal. As the method is influenced by external factors, some measures regarding heat transfer between the handler, surfaces and the animal taken into study have to be taken. The sensitivity of the camera is $0.06^{\circ} \mathrm{C}$ which makes the identification of very small temperature differences from different regions of the body possible. Thermography is also very useful in better understanding the process of thermoregulation and the thermal preferences of different species of reptiles in environments with a good temperature gradient (Tattersall and Cadena, 2010).

\section{MATERIAL AND METHODS}

In this study a total of 10 clinically healthy adult Green Iguanas were used, 9 males and one castrated female, kept in individual vivariums and similar conditions. The images were taken in the morning at 8:00 am and 10:00 am, when the temperature of the vivariums in 3 different spots was also measured (under the light, the feeding bowl site and the coldest spot). The light was turned on every day at 7:15 am and switched off at 9:00 pm which concurred with the same interval that the animals were provided with a basking spot. A total of 6 measurements in six different days were made on a period of 2 weeks, 3 before feeding $(8: 00 \mathrm{am})$ and 3 at $2 \mathrm{~h}$ after the food was offered $(10: 00 \mathrm{am})$. The animals were not force fed to minimize their stress. For the animals that did not eat we excluded those measurements for a better accuracy of the results. The images were taken with the thermographic camera FLIR E6 (FLIR Systems Sweden) outside of the vivariums in an adjacent room at a temperature ranging between $21-24^{\circ} \mathrm{C}$. The animals were handled with gloves and transported in a cardboard box to minimize heat transfer between the handler and the animal that would produce thermal artifacts. For the same reason, a styrofoam slate was placed on the table where we placed the animals for taking the images. The animals were not let to acclimatize, and the pictures were taken at an interval of 2 minutes after they were taken out of the vivarium. A total of 4 images for each animal were taken (up, front, left and right) and the images were analysed with the program FLIR Tools provided by the manufacturer. The temperatures of the body parts that were taken into consideration were head, body on the right side and on the left side respectively. We compared these temperatures between them (before and after the feeding) and with the average of the vivarium temperature taken in three different spots (the basking spot, the site of the feeding bowl and the coldest spot) using an infrared thermometer GM300 (Benetech, China). For each animal we had 3 values of each of these temperatures in both of the moments taken into consideration. In order to analyse the statistical significance of the data we made the arithmetic average of each of these 3 values and the standard deviation (Microsoft Excel) so we ended up having 10 values of the temperature for each body part and vivarium in both of the moments of the study. For the statistical analysis we used the Past program. We analysed the correlation between the body temperatures and the temperatures of the vivarium as well as the $\mathrm{T}$ test between the body temperatures. The obtained data was not included in the Gauss curve so the Spearman correlation was used (Hammer et. al., 2001).

\section{RESULTS AND DISCUSSION}

The average of the head temperature $(\mathrm{Ht})$ before feeding, registered values between $23.47^{\circ} \mathrm{C}$ $( \pm \mathrm{SD}=0.35)$ for the animal $\mathrm{I} 10$ respectively $28.87^{\circ} \mathrm{C}$ $( \pm S D=0.89)$ for the animal I6. After feeding, $\mathrm{Ht}$ registered values between $24.7^{\circ} \mathrm{C}( \pm \mathrm{SD}=1.97)$ for the animal $\mathrm{I} 1$ respectively $32.7^{\circ} \mathrm{C}( \pm \mathrm{SD}=1.49)$ for the animal I7 (Tab. 1).

The average of the body temperature on the right side (Btr) before feeding, registered values between $24^{\circ} \mathrm{C}( \pm \mathrm{SD}=0.51)$ for the animal $\mathrm{I} 10$ respectively $29.27^{\circ} \mathrm{C}( \pm \mathrm{SD}=4.33)$ for the animal I5. After feeding, Btr registered values between $24.65^{\circ} \mathrm{C}( \pm \mathrm{SD}=1.62)$ for the animal I1 respectively $32.7^{\circ} \mathrm{C}( \pm \mathrm{SD}=0.2)$ for the animal I4 (Tab. 1$)$.

The average of the body temperature on the left side (Btl) before feeding, registered values between $23.93^{\circ} \mathrm{C}( \pm \mathrm{SD}=0.4)$ for the animal $\mathrm{I} 10$ respectively $29.67^{\circ} \mathrm{C}( \pm \mathrm{SD}=3.58)$ for the animal 
I5. After feeding, Btl registered values between $25.23^{\circ} \mathrm{C}( \pm \mathrm{SD}=0.2)$ for the animal $\mathrm{I} 10$ respectively $32.47^{\circ} \mathrm{C}( \pm \mathrm{SD}=1.06)$ for the animal I4 (Tab. 1$)$.

The average of the vivariums temperature $(\mathrm{Vt})$ before feeding, registered values between $22.94^{\circ} \mathrm{C}$ $( \pm \mathrm{SD}=1.44)$ for the animal $\mathrm{I} 1$ respectively $27.14^{\circ} \mathrm{C}$ $( \pm S D=0.45)$ for the animal I4. After feeding, $V t$ registered values between $23.52^{\circ} \mathrm{C}( \pm \mathrm{SD}=0.95)$ for the animal $\mathrm{I} 10$ respectively $27.88^{\circ} \mathrm{C}( \pm \mathrm{SD}=0.59)$ for the animal I4 (Tab. 1).

For both moments taken into consideration we obtained a strong relationship between the body temperature and the vivarium temperatures (Tab. 2 and 3).

Using the paired test ( $\mathrm{t}$ test) we obtained a significant difference between the vivarium temperature and the body temperatures ( $\mathrm{p} \leq 0.001)$. This can be linked to the fact that reptiles with a body mass higher than $500 \mathrm{~g}$ are capable of storing heat (Bartholomew and Tucker, 1964).

Before feeding there is no significant difference between the head temperature and the body temperature on the right side $(\mathrm{p}=0.2)$ but there is a significant difference between the head temperature and the body temperature on the left

Tab. 1. The average of the body temperature parts taken into consideration and vivarium temperature

\begin{tabular}{cccccccccccc}
\hline $\mathrm{t}^{0} \mathrm{C}( \pm \mathrm{SD})$ & $\mathrm{I} 1$ & $\mathrm{I} 2$ & $\mathrm{I} 3$ & $\mathrm{I} 4$ & $\mathrm{I} 5$ & $\mathrm{I} 6$ & $\mathrm{I} 7$ & $\mathrm{I} 8$ & $\mathrm{I} 9$ & $\mathrm{I} 10$ & Mean \\
\hline $\begin{array}{c}\text { Before } \\
\text { Feeding }\end{array}$ & & & & & & & & & & & \\
\hline \multirow{2}{*}{$\mathrm{Ht}$} & 23.87 & 25.38 & 25.7 & 28.13 & 28.53 & 28.87 & 27.79 & 24.1 & 27.33 & 23.47 & 26.39 \\
& $(3.15)$ & $(1.72)$ & $(1.55)$ & $(3.36)$ & $(3.88)$ & $(0.89)$ & $(0.55)$ & $(0.36)$ & $(1.51)$ & $(0.35)$ & $(2.05 \pm \mathrm{SD})$ \\
\hline \multirow{2}{*}{$\mathrm{Btr}$} & 24.8 & 26.5 & 26.03 & 28.53 & 29.27 & 28.37 & 27.07 & 24.07 & 27.5 & 24 & 26.61 \\
& $(3.29)$ & $(1.56)$ & $(1.95)$ & $(3.19)$ & $(4.33)$ & $(2.31)$ & $(1.15)$ & $(0.41)$ & $(1.21)$ & $(0.51)$ & $(1.87 \pm \mathrm{SD})$ \\
\hline \multirow{2}{*}{$\mathrm{Btl}$} & 24.9 & 27.57 & 26.7 & 29.57 & 29.67 & 28.73 & 27.77 & 24.43 & 27.78 & 23.93 & 27.11 \\
& $(3.04)$ & $(2.56)$ & $(3.04)$ & $(3.18)$ & $(3.58)$ & $(1.38)$ & $(2.15)$ & $(0.28)$ & $(1.19)$ & $(0.4)$ & $(2.07 \pm \mathrm{SD})$ \\
\hline \multirow{2}{*}{$\mathrm{Vt}$} & 22.94 & 24.01 & 23.94 & 27.14 & 25.33 & 26.16 & 26.64 & 23.5 & 23.92 & 23.53 & 24.71 \\
& $(1.44)$ & $(0.35)$ & $(0.78)$ & $(0.45)$ & $(0.66)$ & $(0.25)$ & $(0.64)$ & $(0.35)$ & $(1.03)$ & $(0.9)$ & $(1.48 \pm \mathrm{SD})$ \\
\hline \multirow{2}{*}{ After } & & & & & & & & & & & \\
feeding & & & & & & & & & & & \\
\multirow{2}{*}{$\mathrm{Ht}$} & 24.7 & 29.4 & \multirow{2}{*}{29.8} & 30.83 & 29.65 & 30.4 & 32.7 & 26.07 & 27.13 & 24.83 & 28.55 \\
& $(1.97)$ & $(1.55)$ & & $(0.85)$ & $(1.2)$ & $(3.95)$ & $(1.49)$ & $(0.05)$ & $(1.04)$ & $(0.28)$ & $(2.71 \pm \mathrm{SD})$ \\
\hline \multirow{2}{*}{$\mathrm{Btr}$} & 24.65 & 29.45 & \multirow{2}{*}{29.2} & 32.7 & 30.15 & 31.3 & 30.5 & 26.67 & 26.83 & 24.93 & 28.63 \\
& $(1.62)$ & $(1.9)$ & & $(0.2)$ & $(0.91)$ & $(3.39)$ & $(0.88)$ & $(0.46)$ & $(0.65)$ & $(0.15)$ & $(2.73 \pm \mathrm{SD})$ \\
\hline \multirow{2}{*}{$\mathrm{Btl}$} & 25.8 & 29.55 & \multirow{2}{*}{30.9} & 32.47 & 30.4 & 31.8 & 30.03 & 27.13 & 28 & 25.23 & 29.13 \\
& $(2.4)$ & $(2.47)$ & & $(1.06)$ & $(1.27)$ & $(2.82)$ & $(1.51)$ & $(0.94)$ & $(0.9)$ & $(0.2)$ & $(2.48 \pm \mathrm{SD})$ \\
\hline \multirow{2}{*}{$\mathrm{Vt}$} & 23.85 & 25.01 & 23.8 & 27.88 & 25.83 & 27.35 & 27.66 & 23.56 & 23.68 & 23.52 & 25.22 \\
& $(1.47)$ & $(1.96)$ & $(1.87)$ & $(0.59)$ & $(1.02)$ & $(0.74)$ & $(1.13)$ & $(0.83)$ & $(0.94)$ & $(0.95)$ & $(1.83 \pm \mathrm{SD})$ \\
\hline
\end{tabular}

I1-Iguana 1 etc.; Ht-head temperature; Btr-body temperature on the right side; Btl-body temperature on the left side; Vt-average vivarium temperature.

Tab. 2. Spearman correlation before feeding

\begin{tabular}{ccccc}
\hline 0 & $\mathrm{Ht}$ & $\mathrm{Btr}$ & $\mathrm{Btl}$ & $\mathrm{Vt}$ \\
\hline $\mathrm{Ht}$ & 0 & $<0.001$ & $<0.001$ & 0.003 \\
\hline $\mathrm{Btr}$ & 0.9394 & 0 & 0 & 0.009 \\
\hline $\mathrm{Btl}$ & 0.9394 & 1 & 0 & 0.009 \\
\hline $\mathrm{Vt}$ & 0.8303 & 0.7697 & 0.7697 & 0 \\
\hline
\end{tabular}

Ht-head temperature; Btr-body temperature on the right side; BtIbody temperature on the left side; Vt-average vivarium temperature.
Tab. 3. Spearman correlation after the feeding

\begin{tabular}{ccccc}
\hline 0 & $\mathrm{Ht}$ & $\mathrm{Btr}$ & $\mathrm{Btl}$ & $\mathrm{Vt}$ \\
\hline $\mathrm{Ht}$ & 0 & $<0.001$ & 0.001 & 0.005 \\
\hline $\mathrm{Btr}$ & 0.9273 & 0 & $<0.001$ & 0.001 \\
\hline $\mathrm{Btl}$ & 0.8667 & 0.9030 & 0 & 0.009 \\
\hline $\mathrm{Vt}$ & 0.8061 & 0.8667 & 0.7697 & 0 \\
\hline Ht-head temperature; Btr-body temperature on the right side; Btl-
\end{tabular}

body temperature on the left side; Vt-average vivarium temperature. 
side $(\mathrm{p}=0.005)$. After feeding there is no significant difference between the head temperature and the body temperature on the right side $(p=0.8)$ respectively between the head temperature and the body temperature on the left side $(p=0.2)$. A difference in the head and body temperature was proven in different species of reptiles (Webb and Heatwole, 1971; Johnson, 1972, 1973; Webb and Johnson 1972a, 1972b) and as well in reptiles that live in a temperate environment (Sannolo et. al., 2014). In most of the cases, this can be due to cooling in the thermoregulatory process (Johnson 1974; Tattersall et. al., 2006).

The $\mathrm{T}$ test showed statistical significant differences between the body temperatures before and after the feeding. The $\mathrm{p}$ value between the head temperatures was 0.002 , between the body temperatures on the right side 0.004 and between the body temperatures on the left side $<0.001$. Significant difference was obtained between the vivarium temperatures as well $\mathrm{p}=0.02$.

However there is a significant difference between the body temperature on the right side and the left side both before $(p=0.002)$ and after feeding $(\mathrm{p}=0.04)$ which could be due to the organ topography in the coelomic cavity (Simth et. al., 2001).

\section{CONCLUSIONS}

Green iguanas as well as other reptiles have a head temperature lower than the body temperature. They maintain a body temperature significantly higher than the average of the vivarium temperature which proves that they can store heat. The body temperature was significantly higher after feeding which may indicate a need of a higher temperature for a proper digestion. The higher temperature in the left flank can be related to the topography of the descending part of the stomach in that region.

\section{REFRENCES}

1. Bartholomew GA, Tucker VA (1964). Size. Body temperature, thermal conductance, oxygen consumption, and heart rate in Australian varanid lizards. Physiol Zool 37. 341-354.

2. Brattstorm BH (1965). Body temperatures of reptiles. American Midland Naturalist Vol 73 No 2 pp 376-422.

3. Hammer O, Harper DAT, Ryan PD (2001). PAST: Paleontological Statistics software package for education and data analysis. Paleontologia Electronica 4(1):9.

4. Harlow HJ, Hillman SS, Hoffman M (1976). The effect of temperature on digestive efficiency in the herbivorous lizard, Dipsosaurus dorsalis. Journal of comparative physiology 111 1-6.

5. Johnson CR (1974). Thermoregulation in Crocodilians-i. Head-body temperature control in the Papuan-New Guinean crocodiles, Crocodylus novaeguineae and Crocodylus porosus. Camp B\&hem Physiol 49A:3-28.

6. Johnson CR (1972). Head-body temperature differences in Varanus gouldii (Sauria : Varanidae). Comp Biochem Physiol A 43A:1025-1029.

7. Johnson CR (1973). Thermoregulation in pythons II. Head-body temperature differences and thermal preferenda in Australian pythons. Comp Biochem Physiol A 45:1064-1087.

8. Smith D, Dobson H, Spence E (2001). Gastrointestinal Studies In The Green Iguana: Technique And Reference Values. Veterinary Radiology \& Ultrasound 42: 515-520.

9. Tattersall GJ, Cadena V (2010). Insights into animal temperature adaptations revealed through thermal imaging. The Imaging Science Journal 58:261-268.

10. Tattersall GJ, Cadena V, Skinner M.C (2006). Respiratory cooling and thermoregulatory coupling in reptiles. Respir Physiol Neurobiol 154:302-318.

11. Webb GJW, Heatwole H (1971). Patterns of heat distribution within the bodies of some Australian pythons Copeia 209-220.

12. Webb GJW, Johnson CR (1972). Head-body temperature differences in turtles. Comp Biochem Physiol A 48A:593611.

13. Webb GJW, Johnson CR, Firth BT (1972). Head body temperature differences in lizards. Physiol Zool 45:130142. 